\title{
Development Trend Study of Divergent Thinking among Students from Primary to Middle School
}

\author{
Weidong $\mathrm{Wu}$ \\ Education Department of Dezhou University, Dezhou 253023, Shandong, China \\ E-mail: wwd0911@sohu.com
}

\begin{abstract}
In the present study, Williams' activities test of creative thinking applied as a research tool, every grade students from the fourth grade in primary school to the third grade in middle school were selected to implement measurement, after statistical analysis we found that: (1) divergent thinking trends in various components were inconsistent. (2) There were significant gender differences among flexibility, original creativity and the titling capacity and no significant gender difference among fluency, openness and elaboration.
\end{abstract}

Keywords: Students, Divergent thinking, Development, Gender difference

\section{Introduction}

Divergent thinking is the core component of creativity, including capacities such as fluency, flexibility, original creativity and so on. Celebrated creativity expert of American, Williams, has developed a Williams creative thinking test to measure the activities of the various components of divergent thinking. In the present study this test applied as a tool, development trend of divergent thinking among students from primary to middle school was investigated, with attempts to further reveal development law of creativity and thus offer some basis for the cultivation of creativity.

\section{Materials and methods}

\subsection{Measurement Tools}

Williams' creative thinking activities test modified by Taiwan's Hsin-Tai Lin, Mu-rong Wang was applied in the present study, and six divergent thinking scores, such as fluency, openness, flexibility, original creativity and precision could be observed.

\subsection{Measurement}

One class per grade was selected from the fourth grade in primary school to the third grade in middle school to undertake observation. Number of each grade was as follows: 57, 63 and 60 in the fourth, fifth and sixth grade of primary school respectively; 60, 62 and 55 in the first, second and third grade of Middle school respectively.

\subsection{Measurement process}

Test manner was group measurement, and the whole measurement process would take about 20-30 minutes.

\subsection{Grading method}

Grading of Williams' creative thinking activities test was based on students' implementation of 12 uncompleted graphs, and then each student was graded according to the given grading standard respectively.

Williams' creative thinking activities test was a subjective questionnaire, according to the grading requirements of subjective test imposed by surveying, questionnaires of 61 students from one class were graded by me and my fellow respectively, through iterated grading for many times and discussing and studying of grading standard until we got a consistency of grading result over 0.9 , only based on this, we formally started to grade the questionnaires of all grades.

\subsection{Statistical analysis}

Data was processed using the software of SPSS for windows 11.5.

\section{Results and analysis}

\subsection{Development trend analysis of various components of divergent thinking}

Score of creative thinking activities test possessed two kinds of attributes. Fluency score was based on the standard of response magnitude, while scores of other five aspects belonged to the data of quality domain. 
Consequently, total scale score could not be added up by all six aspects, and total scale score analysis was unable to carry out.

\subsubsection{Grades development trend analysis of fluency}

After the statistical processing of the fluency scores in various grades, the average fluency score of each grade was obtained, and corresponding results were listed in Table 1 in detail.

Through the variance analysis of the average each grade, there were significant differences among grades. Fluency score of various grades were undertaken multiple comparison, and results were listed in Table 2 in detail.

As seen from Table 2, students from the fourth grade in primary school had the highest level of fluency, significantly higher than other grades excluding students from the third grade in middle school; Fluency level of students from the fifth grade in primary school decreased significantly and attained the bottom. Fluency level from the fifth grade in primary to the third grade in middle school showed an increasing trend, but there were no significant differences among them.

\subsubsection{Grades development trend analysis of openness}

The openness average of various grades and multiple comparisons among grades were listed in Table 3 and 4 in detail.

As seen from Table 3 and 4, from the fourth grade in primary school to the third grade in middle school, the openness level of all grades showed a fluctuated trend; there were no significant differences among three grades of primary school. Openness level from the first grade in middle school decreased significantly compared to the sixth grade in primary school; there were no significant differences among grades of middle school, but the whole level in middle school was no better than primary school.

\subsubsection{Grades development trend analysis of flexibility}

The flexibility average of various grades and multiple comparisons among grades were listed in Table 5 and 6 in detail.

As seen from Table 5 and 6, in the aspect of flexibility, students from the fourth grade showed a highest level, while students from the fifth grade decreased significantly and from the sixth grade increased in primary school. In middle school, the third grade increased slightly compared to the other two grades with no significant differences.

\subsubsection{Grades development trend analysis of original creativity}

The original creativity average of various grades and multiple comparisons among grades were listed in Table 7 and 8 in detail.

As seen from Table 7 and 8, from the fourth grade in primary school to the third grade in middle school, the openness level of all grades showed an ascending trend; students from the third grade in middle school showed a highest level. There were no significant differences from the fourth grade in primary school to the first grade in middle school. Down to the third grade in middle school, the original creativity level was significantly higher than other grades excluding the second grade in middle school.

\subsubsection{Grades development trend analysis of elaboration}

The elaboration average of various grades and multiple comparisons among grades were listed in Table 9 and 10 in detail.

As seen from Table 9 and 10, from the fourth grade in primary school to the third grade in middle school, the elaboration level of all grades showed a decreasing trend; students from the fourth grade in primary school showed a highest level, then decreased gradually in an descending trend until the first grade in middle school with significant differences among grades. From the first to third grade in middle school, the elaboration level showed a fluctuated trend without significant differences among grades.

3.1.6 Grades development trend analysis of titling capacity

The titling capacity average of various grades and multiple comparisons among grades were listed in Table 11 and 12 in detail.

As seen from Table 11 and 12, in primary school, there was no significant difference between the fourth and fifth grade, and significant differences between the sixth and the fourth, the sixth and the fifth grade. Title score of students from the sixth grade increased; in middle school, the average of all grades showed a fluctuated trend 
without significant differences among them. Students from the second grade showed the highest level, and significantly increased compared to the fourth and fifth grades in primary school. The whole middle school showed an ascending trend compared to primary school.

\subsection{Gender characteristics analysis of divergent thinking level}

Scores of students from different gender in various aspects of creative thinking activities were undertaken difference test, and results were listed in Table 13 in detail.

As seen from Table 13, there were no significant differences in fluency, openness and elaboration among boys and girls; while significant differences in flexibility, original creativity and titling capacity. The flexibility and original creativity of boys were significantly higher than girls, while the titling capacity of girls was significantly higher than boys.

\section{Discussions}

\subsection{The development trend of divergent thinking and causation analysis}

(1) In the flexibility, fluency, openness and elaboration aspects, the highest level appeared in primary schools, and the whole level of middle school was no higher than primary school. Among them, elaboration level showed a significant descending trend with the increasing of grade. There were reasons as follows: first of all, due to the lower socialization level, ideology of students in primary didn't have so much norm constraint, while older, more people tend to act in accordance with specifications. After the entry from primary to middle school, children showed a consistent trend for code of conduct, and their thinking has become more robust and normal. In addition, some people thought that the situation could be mainly ascribed to the advent of puberty, social pressures, school pressures, and teachers' pressure which played a limited role in the creativity of middle school students (Hu, 2003, PP. 775-777). For understanding problems, students were better at starting with detail and part.

(2) Some components of divergent thinking increased with the increasing of grades. For instance, in the titling capacity level, titles of graphs named by students in primary school were more specific and visual, while titles by students in middle school were more abstract and general. This feature was attributed to the psychological characteristics of thinking developed from specific vividness to abstract generality with the increasing of individual age.

Changes of original creativity also showed an increasing trend, which could be attributable to the fact that students in middle school were better at digesting and mastering knowledge and adept at recombination of existing knowledge with the continuous improvement of knowledge level.

(3) In middle school, there was no significant difference among grades. Due to the puberty, psychological contradiction was very prominent among students, variation and fluctuation of psychological characteristics were considerable, which often affected, even stagnated divergent thinking.

(4) Gender characteristics of divergent thinking and causations

The present study shows that flexibility and original creativity of boys were significantly higher than girls, while titling capacity of girls was higher than boys. There were no significant differences in fluency, openness and elaboration between boys and girls. The reasons for the gender differences in divergent thinking were as follows: firstly, genetic and physiological differences between boys and girls had an impact. Secondly, there was a tremendous difference in intellectual development and various special abilities between boys and girls (Zhang, 2002, PP. 40-44); some scholars might consider that the social expectations for gender roles of boys and girls were different, especially for the traditional concept of gender roles which was propitious to the creativity development of boys while inhibited that of girls (Tong, 2002, PP. 22-25).

\subsection{Implications for education in the present study}

Schools should pay attention to training the divergent thinking of students in the understanding. With the increasing of age, divergent thinking level of students failed to attain an overall improvement quite consistently, and showed a decreasing trend or even stagnant trend in certain aspects. Such a development characteristics was just in accordance with the heavier and heavier pressure of students for entering higher school. In primary school, due to lower pressure for entering higher school, the fact that creativity in most aspects showed the highest level just proved that. Exam-oriented education has long cultivated a large number of students with higher score and less capability and people with inadequate creativity. It aimed to entering higher school, severely constrained the creativity of students, and was not conducive to the cultivating of new type creative talents. Therefore, as a dominant factor to promote human psychological development, schools should change from exam-oriented 
education into comprehensive quality-oriented education in order to develop students completely.

Divergent thinking training and educational pertinence should be intensified. The creativity of students was closely associated with the creative ideas and attitudes of teachers. Teachers should have a strong sense of cultivating creativity, meanwhile, in combination with the characteristics of the current subject, create situations which were in favor of cultivating creative thinking of students and stimulate students' creation desire. Teachers also should enhance the creative qualities such as flexibility, openness, original creativity and so on during the process of solving problems, through classroom teaching and extracurricular activities. Educators should pay special attention to the low tide period and plateau phase of various components development, through analyzing the causations for low tide and stagnant stage, eliminate the unfavorable factors in order to offer better conditions for ameliorating the divergent thinking level of students.

\section{Conclusions}

5.1 From primary to middle school, various components development of divergent thinking showed an inconsistent trend. Flexibility, fluency, openness and elaboration level of students from middle school was no higher than students from primary school; original creativity and titling capacity gradually increased with the increasing of grades.

5.2 There were significant gender differences in flexibility, original creativity and titling capacity while no significant differences in fluency, openness and precision.

\section{References}

Hu, W.P., \& Lin, C.D. (2003). A developmental research on the scientific creativity of British adolescents. Acta Psychologica Sinica, (5):775-777.

Tong, X.Y., \& Wo, J.Z. (2002). Research on the students' development of creativity thinking in senior high school. Psychological Development and Education, (2):22-25.

Zhang, Z.Y. (2002). A psychological study on creativity. Liaoning Education Research, (60):40-44.

Table 1. Fluency average of all grades

\begin{tabular}{|c|c|c|c|c|c|c|}
\hline & P4 & P5 & P6 & M1 & M2 & M3 \\
\hline $\mathrm{N}$ & 57 & 63 & 60 & 60 & 62 & 55 \\
\hline $\mathrm{M}$ & 11.98 & 10.92 & 11.20 & 11.30 & 11.37 & 11.53 \\
\hline
\end{tabular}

Note: P4: The fourth grade in primary school

P5: The fifth grade in primary school

P6: The sixth grade in primary school

M1: The first grade in middle school

M2: The second grade in middle school

M3: The third grade in middle school

The same as follows.

Table 2. Fluency average difference comparison of all grades

\begin{tabular}{|lllllll|}
\hline & P5 & P6 & M1 & M2 & M3 \\
\hline P4 $1.06^{* *}$ & $.78^{* *}$ & $.68^{*}$ & $.61^{*}$ & .46 \\
P5 & & -.28 & -.38 & -.45 & -.61 \\
P6 & & & -.10 & -.17 & -.33 \\
M1 & & & -7.10 & -.23 \\
M2 & & & & & -.16 \\
\hline
\end{tabular}

$* \mathrm{p}<0.05 ; * * \mathrm{p}<0.01$

Table 3. Openness average of all grades

\begin{tabular}{|c|c|c|c|c|c|c|}
\hline & P4 & P5 & P6 & M1 & M2 & M3 \\
\hline $\mathrm{N}$ & 57 & 63 & 60 & 60 & 62 & 55 \\
\hline $\mathrm{M}$ & 22.56 & 21.49 & 24.23 & 20.10 & 21.58 & 21.47 \\
\hline
\end{tabular}


Table 4. Openness average difference comparison of all grades

\begin{tabular}{|ccccccc|}
\hline & P5 & P6 & M1 & M2 & M3 \\
\hline P4 & 1.07 & -1.67 & 2.46 & .98 & 1.09 \\
P5 & & -2.74 & 1.39 & -8.86 & 1.93 \\
P6 & & & $4.13^{* *}$ & 2.65 & $2.76^{*}$ \\
M1 & & & & -1.48 & -1.37 \\
M2 & & & & & .11 \\
\hline
\end{tabular}

$* \mathrm{p}<0.05 ; * * \mathrm{p}<0.01$

Table 5. Flexibility average of all grades

\begin{tabular}{|c|c|c|c|c|c|c|}
\hline & P4 & P5 & P6 & M1 & M2 & M3 \\
\hline $\mathrm{N}$ & 57 & 63 & 60 & 60 & 62 & 55 \\
\hline $\mathrm{M}$ & 7.39 & 6.22 & 6.97 & 7.00 & 6.85 & 7.18 \\
\hline
\end{tabular}

Table 6. Flexibility average difference comparison of all grades

\begin{tabular}{|lllllll|}
\hline & P5 & P6 & M1 & M2 & M3 \\
\hline P4 $1.16^{* *}$ & .42 & .39 & .53 & .20 \\
P5 & & -.74 & -.78 & -.63 & $-.96^{*}$ \\
P6 & & & 3.33 & .11 & -.22 \\
M1 & & & & .15 & -.18 \\
M2 & & & & & -.33 \\
\hline
\end{tabular}

$* \mathrm{p}<0.05 ; * * \mathrm{p}<0.01$

Table 7 . Original creativity average of all grades

\begin{tabular}{|c|c|r|r|r|c|c|}
\hline & P4 & P5 & P6 & M1 & M2 & M3 \\
\hline $\mathrm{N}$ & 57 & 63 & 60 & 60 & 62 & 55 \\
\hline $\mathrm{M}$ & 10.79 & 11.97 & 11.33 & 12.45 & 15.37 & 16.00 \\
\hline
\end{tabular}

Table 8. Original creativity average difference comparison of all grades

\begin{tabular}{|c|c|c|c|c|c|}
\hline & P5 & P6 & M1 & M2 & M3 \\
\hline P4 & -1.19 & -.54 & -1.66 & $-4.58 * *$ & $-5.21 * *$ \\
\hline P5 & & .63 & -.48 & $-3.40^{*}$ & $-4.03 * *$ \\
\hline P6 & & & -1.12 & $-4.04^{* *}$ & $-4.67^{* *}$ \\
\hline M1 & & & & -2.92 & $-3.55^{* *}$ \\
\hline M2 & & & & & -.63 \\
\hline
\end{tabular}

$* \mathrm{p}<0.05 ; * * \mathrm{p}<0.01$

Table 9. Elaboration average of all grades

\begin{tabular}{|c|c|c|c|c|c|c|}
\hline & P4 & P5 & P6 & M1 & M2 & M3 \\
\hline $\mathrm{N}$ & 57 & 63 & 60 & 60 & 62 & 55 \\
\hline $\mathrm{M}$ & 9.96 & 8.89 & 6.93 & 4.93 & 6.60 & 5.24 \\
\hline
\end{tabular}


Table 10. Elaboration average difference comparison of all grades

\begin{tabular}{|cccccc|}
\hline & P5 & P6 & M1 & M2 & M3 \\
\hline P4 & 1.08 & $3.03^{* *}$ & $5.03^{* *}$ & $3.37^{* *}$ & $4.73^{* *}$ \\
P5 & & $1.96^{*}$ & $3.96^{* *}$ & $2.29 *$ & $3.65^{* *}$ \\
P6 & & & $2.00^{*}$ & .37 & 1.70 \\
M1 & & & & -1.66 & -.30 \\
M2 & & & & & 1.36 \\
\hline
\end{tabular}

$* \mathrm{p}<0.05 ; * * \mathrm{p}<0.01$

Table 11. Title score average of all grades

\begin{tabular}{|c|c|c|c|c|c|c|}
\hline & P4 & P5 & P6 & M1 & M2 & M3 \\
\hline $\mathrm{N}$ & 57 & 63 & 60 & 60 & 62 & 55 \\
\hline $\mathrm{M}$ & 14.60 & 14.43 & 18.63 & 15.90 & 18.50 & 16.65 \\
\hline
\end{tabular}

Table 12. Title score average difference comparison of all grades

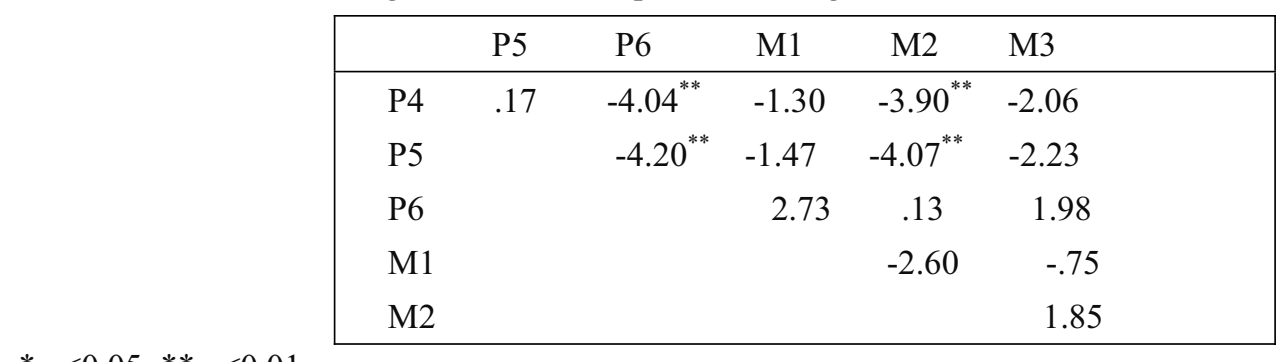

$* \mathrm{p}<0.05 ; * * \mathrm{p}<0.01$

Table 13. Difference test of creative thinking activities score in gender

\begin{tabular}{|c|c|c|c|c|c|c|c|c|c|c|c|c|}
\hline & \multicolumn{2}{|c|}{ Fluency } & \multicolumn{2}{|c|}{ Openness } & \multicolumn{2}{|c|}{ Flexibility } & \multicolumn{2}{|c|}{ Original creativity } & \multicolumn{2}{|c|}{ Precision } & \multicolumn{2}{|c|}{$\underline{\text { Title }}$} \\
\hline & B & G & B & G & $\mathrm{B}$ & G & $\mathrm{B}$ & G & B & G & B & G \\
\hline M & 11.51 & 11.23 & 21.75 & 22.05 & 7.14 & 6.71 & 13.61 & 12.33 & 7.14 & 7.07 & 15.82 & 17.08 \\
\hline $\mathrm{SD}$ & 1.20 & 1.54 & 4.95 & 5.15 & 1.57 & 1.62 & 5.17 & 5.16 & 4.03 & 3.70 & 4.64 & 5.14 \\
\hline $\mathrm{t}$ & 1.9 & & -.56 & & 2.5 & & 2.3 & $34^{*}$ & & 17 & & $-2.43^{*}$ \\
\hline
\end{tabular}

